\title{
Histologic Evaluation of the Gastrointestinal Tract and Pancreatic Changes After Laparoscopy-Assisted Distal Gastrectomy in Canine Model
}

\author{
Jalal Bakhtiari ${ }^{1,2^{*}}$, Mahboubeh Abdi ${ }^{1}$, Mohammad Javad Gharagozlou ${ }^{3}$, Ali Reza Khalaj ${ }^{2,4}$ \\ ${ }^{1}$ Department of Clinical Sciences, Faculty of Veterinary Medicine, University of Tehran, Tehran, IR Iran \\ ${ }^{2}$ Minimally Invasive Surgery Research Center, Rasool Akram Hospital, Tehran University of Medical Sciences, Tehran, IR Iran \\ ${ }^{3}$ Department of Pathobiology, Faculty of Veterinary Medicine, University of Tehran, Tehran, IR Iran \\ ${ }^{4}$ Department of Surgery, Faculty of Medicine, Shahed University of Medical Sciences, Tehran, IR Iran
}

\begin{tabular}{l}
\hline A R T I C L E I N F O \\
\hline Article type: \\
Original Article \\
\hline Article history: \\
Received: 04 Jul 201 \\
Revised: 29 Nov 2011 \\
Accepted: 21 Dec 2011 \\
\hline
\end{tabular}

Keywords:

Dog Diseases

Laparoscopy

Gastrectomy

\begin{abstract}
A B S T R A C T
Background: Total and partial gastrectomy is commonly used to treat gastric carcinoma or other benign or malignant conditions of the stomach. Laparoscopic-assisted distal gastrectomy is an alternative approach for treating mucosal gastric cancer. Many investigators have assessed the safety, efficacy, and feasibility of this procedure.

Objectives: The aim of present study is to compare the outcomes obtained using Roux-en-Y and Jejunal Loop Interposition reconstructive techniques after laparoscopic-assisted distal gastrectomy and determine the gross pathologic and histological changes in the anastomotic area and the macroscopic and microscopic pancreatic changes 1 and 3 months after the surgery.

Materials and Methods: Twelve adult healthy male mixed-breed dogs were divided randomly into 2 groups of 6 animals each. In group A, left gastroepiploic vessel and its branches, gastroepiploic ligament, and right gastroepiploic vessels were ligated and resected laparoscopically. A loop of jejunum, $20 \mathrm{~cm}$ distal to the Treitz ligament, was resected and end-to-side anastomosis was performed between the distal jejunal end and remaining part of the stomach. The proximal jejunal end was end-to-side anastomosed to the rest of the jejunum. In group B, gastrectomy was performed in the same manner. A 20-cm jejunal loop, $20 \mathrm{~cm}$ from the Treitz ligament, was resected, and the remaining part of the stomach and jejunum was anastomosed. Jejunojejunostomy was performed between the two remaining jejunal parts. Results: Esophagoscopy showed no en bloc resection of the esophagus or alkaline gastritis. A 2-cm by 2-cm ulcerative mass was observed in the remaining part of the stomach close to gastrojejunal anastomotic site in one patient of group A. The animals were authanized one and three month after the surgery. Macroscopic evaluation revealed normal healing of the incisional scars without any inflammation, abscess, adhesion, or other acute or chronic inflammatory reactions. Microscopic evaluation of the pancreatic sections revealed normal appearance of the gland structure, Langerhans islets, and ductal systems without any inflammatory reaction. Decrease in the number of zymogen granules was noted in most of the cases. The junction between the esophagus and stomach was normal in all the cases, and no inflammatory, degenerative, proliferative, hypoplastic, necrotic, hemorrhagic, edemic, and ulcerative changes were noted. There were no pathologic abnormalities in any of the esophagogastric junction sections. In the gastrojejunal anastomotic sites, decreased stomach thickness at the anastomotic site and cystic dilatation of the jejunal crypts was noted. Conclusions: Upper gastrointestinal endoscopy was found to be a useful and feasible technique to detect esophageal gastritis; anatomical structure, obstruction, or stenosis; and other disorders of the upper gastrointestinal tract. In addition, the 2 reconstructive techniques used following gastrectomy yielded similar endoscopic and pathologic findings.
\end{abstract}

* Corresponding author: Jalal Bakhtiari, Department of Clinical Sciences, Faculty of Veterinary Medicine, University of Tehran, Tehran, IR Iran. Tel: +98-61117121, Fax:+98-2166438327, E-mail: bakhtiar@ut.ac.ir 
- Implication for health policy/practice/research/medical education:

Minimally invasive surgery has evolved over the last three decades, and this continues today. total and partial gastrectomy is commonly used to treat gastric carcinoma or other benign or malignant conditions of the stomach. Laparoscopic assisted distal gastrectomy (LADG) is an alternative treatment approach for mucosal gastric cancer. This experimental laparoscopic surgery in canine model is clearly indicated for surgical therapy in stomach cancers and morbidly obese patients /animals who fail to respond to dietary, behavioral, nutritional, and medical therapies. The readers of this article are medical and veterinary surgeons and experimental pathologist.

- Please cite this paperas:

Bakhtiari J, Abdi M, Gharagozlou MJ, Khalaj AR. Histologic Evaluation of the Gastrointestinal Tract and Pancreatic Changes After Laparoscopy-Assisted Distal Gastrectomy in Canine Model.J Minim Invasive Surg Sci. 2012;1(1):11-6. DOI:10.5812/jmiss.1793

\section{Background}

Total and partial gastrectomy is commonly used to treat gastric carcinoma or other benign or malignant conditions of the stomach (1). Laparoscopic-assisted distal gastrectomy (LADG) is an alternative treatment approach for mucosal gastric cancer, and many investigators have assessed the safety, efficacy, and feasibility of this procedure (2). Several studies have shown that better clinical results were obtained and immune responses were preserved in laparoscopic surgeries than in laparotomies (3-6). The first successful gastrectomy was performed in 1881 by Theodor Billroth for the treatment of gastric cancer, and the first laparoscopicassisted distal gastrectomy was performed in 1991 by Kitano for the treatment of early gastric cancer (7). In 1950, Frank Lahey performed radical total gastrectomy to treat gastric cancer and described the pathologic features of the disease (8). One of the complications associated with gastrectomy is reflux esophagitis; it plays an important role in determining the postoperative quality of life of patients $(9,10)$. The patients developing reflux esophagitis experience chest pain, epigastralgia, heartburn, etc (11). In addition, esophageal mucosal damage probably occurs because of the activity of bile acids and pancreatic enzymes (10-13). Another complication of gastrectomy and the main reason for postoperative morbidity and death is leakage (14-17). Anastomotic blood flow and collagen metabolism are the factors that influence the outcomes of different techniques used for anastomosis $(16,17)$.

Several studies have indicated that gastrectomy is an important risk factor for pancreatic cancer (18-20). Watanapa and Williamson have reported that partial gastrectomy can increase cholecystokinin (CCK) release, stimulate pancreatic growth, and induce carcinogenesis $(10,21)$. Many methods have been described to reconstruct the digestive system after gastrectomy, but an ideal one is still controversial $(9,22,23)$. Some studies have shown the Roux-en-Y gastrojejunostomy is the most effective technique to treat and prevent reflux gastritis (24). Moreover, several techniques such as hand-sewn sutures or stapler anastomosis are used for anastomosis after gastrectomy to reduce negative outcomes (25-27).

\section{Objectives}

The aim of the present study is to compare the outcomes of 2 reconstructive techniques-Roux-en-Y (R\&Y) and Jejunal Loop Interposition (JLI)-after laparoscopicassisted distal gastrectomy and determine the gross pathologic and histological changes in the anastomotic area and the macroscopic and microscopic changes in the pancreas 1 and 3 months after the surgery.

\section{Materials and Methods}

Twelve adult healthy male-mixed breed dogs were used for this study. The study design was approved by the ethics guidelines of the University Research Committee. The dogs were divided randomly into two groups of 6 animals each. Food intake was restricted $12 \mathrm{~h}$ before the surgery. All the animals were injected with ketamine hydrochloride (10 mg/kg), acepromasine ( $0.02 \mathrm{mg} / \mathrm{kg}$ ), and atropine $(0.05 \mathrm{mg} / \mathrm{kg})$ and maintained in dorsal recumbence. Cefazolin $(20 \mathrm{mg} / \mathrm{kg})$ was injected intravascularly as a prophylactic antibiotic. Anesthesia was inducted with thiopental sodium (10 $\mathrm{mg} / \mathrm{kg}$, intravenous) and maintained with halothane and $30 \%$ oxygen. Fluid losses were replaced with intravenous ringer lactate solution. Pneumoperitoneum was established using a Veress needle, and inter-peritoneal pressure was maintained at $14 \mathrm{mmHg}$. A 10-mm trocar was placed at the umbilical

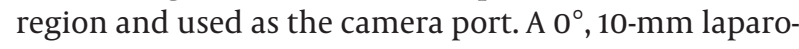
scopic telescope (Richard Wolf Co) was placed in the 10$\mathrm{mm}$ trocar, and exploratory laparoscopy was performed before the surgery. Next, two 5-mm trocars were placed in the one-third upper left and right midline of the abdomen.

In group A (R\&Y), left gastroepiploic vessel and its branches were ligated and resected. Next, gastroepiploic ligament and right gastroepiploic vessels were resected precisely. Subsequently, the stomach was freed from all its attachments, and gastrectomy was performed. A 5-cm incision was made on the first laparoscopic trocar, and the stomach was removed from this mini-laparotomy incision. Anastomosis was then performed extracorporeally by hand sewing. After gastrectomy, the duodenal end was closed using a 2-layer inverting suture pattern. Next, a loop of jejunum, 20-cm distal to the Treitz ligament, 


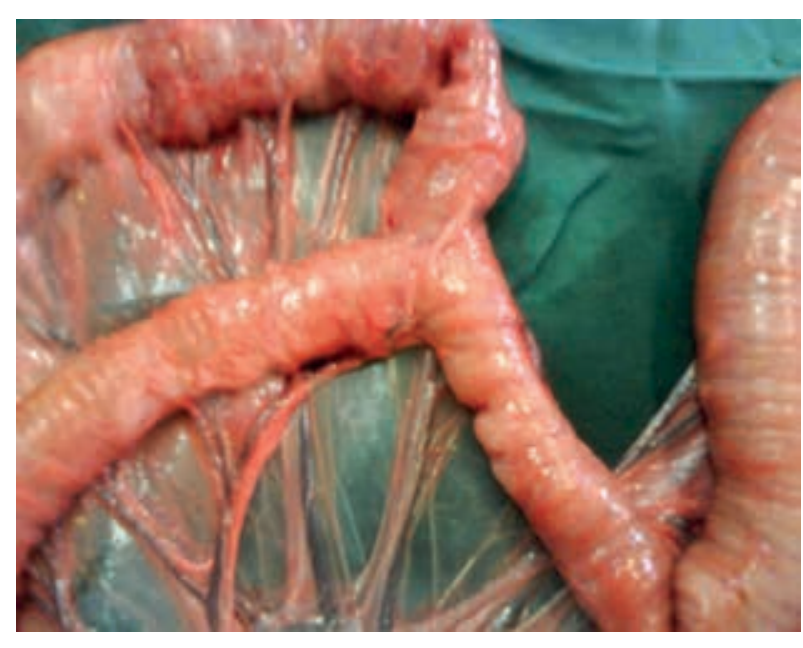

Figure 1. Macroscopic Features of the R\&Y Group 1 Month After Surgery

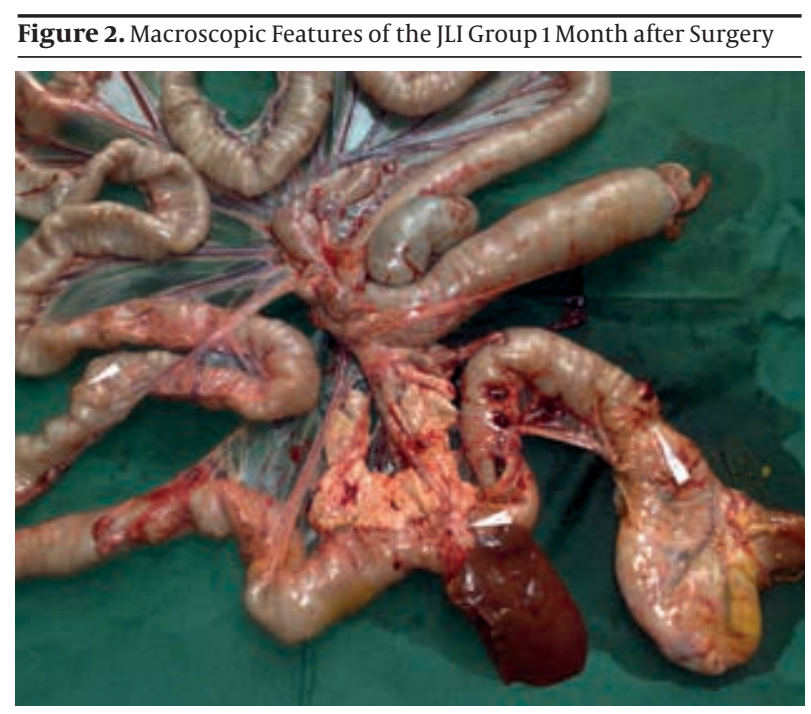

Arrows show the locations of jejonal loop anastomosis

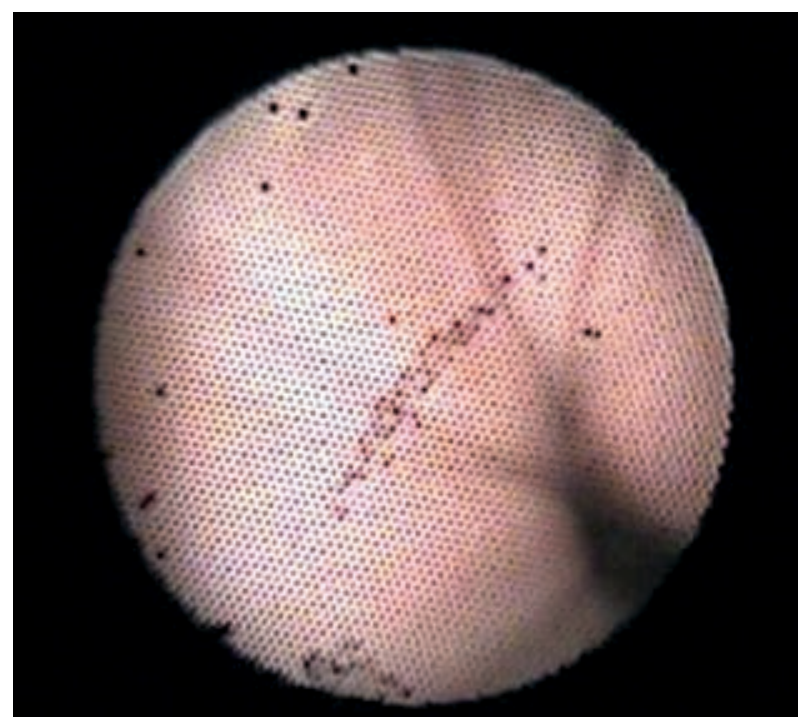

Figure 3. No Evidence of Reflux Esophagitis Under Esophagoscopy View was identified and resected. End-to-side anastomosis was performed between the distal jejunal end and remaining part of the stomach. The proximal jejunal end was endto-side anastomosed to the rest of the jejunum. In group $\mathrm{B}$ (JLI), gastrectomy was performed in the same manner. The jejunal loop interposition was used to reconstruct the bowel. A 20-cm long jejunum was resected from a $20 \mathrm{~cm}$ distance to the Treitz ligament. The proximal end of the jejunal loop was end-to-side anastomosed to the remaining part of the stomach, and the distal end was anastomosed to the proximal jejunum. Finally, jejunojejunostomy was performed between the 2 jejunal parts. The abdomen was lavaged and closed in a routine manner. Food intake was allowed 2 days after the surgery. On a third postoperative day, the animals were fed a small volume of soft blended food. The body temperature, heart rate, and respiratory rate of all the animals were monitored daily during the study period.

Esophagoscopy and gastroscopic evaluation was performed on day 28 after the surgery by using a flexible endoscope (Vetvu-Swiss) to determine the morphology of the interposed segment, status of the enterogastric biliary reflux (EBR), and presence of esophagitis reflux (ER). Three animals each from groups A and B were authanized 30 days after the surgery, and the others were authanized 90 days after the operation by using magnesium sulfate. The abdomen was opened, gross abnormalities were recorded, and a ligation suture was placed in the distal parts of the esophagus and jejunum after the jejunojejunal anastomosis (Figures 1 and 2). The esophagus; the remaining part of the stomach, duodenum, and jejunum, including all the anastomotic sites; and pieces of the liver, pancreas, spleen, and regional lymph nodes were excised, washed, and placed in 10\% formalin. After fixation, the organs were cut at 3-mm intervals along their length, embedded in paraffin, five micron thick paraffin sections were cut from paraffin blocks and stained with hematoxylin and eosin method.

\section{Results}

No complications occurred during the surgeries and recovery from anesthesia. There was no evidence of wound infection or dehiscence in the animals. Body temperature, heart rate, and respiratory rate were in the normal range during the study. All animals were able to resume oral intake of food at the third postoperative day, although the food intake was lesser than that during preoperative days. One animal from group A and two animals from group B experienced nausea, regurgitation, diarrhea, and weakness that were managed by conservative therapy. Esophagoscopy and gastroscopy performed 28 days after the operation revealed normal gastrodeudenal and duodenojejunal anastomotic junctions. There was no report of EBR in the esophagus or alkaline gastritis (Figure 3). A 2-cm by 2 -cm ulcer was observed in the remaining part of the stomach close to the gastrojejunal anastomotic site in 


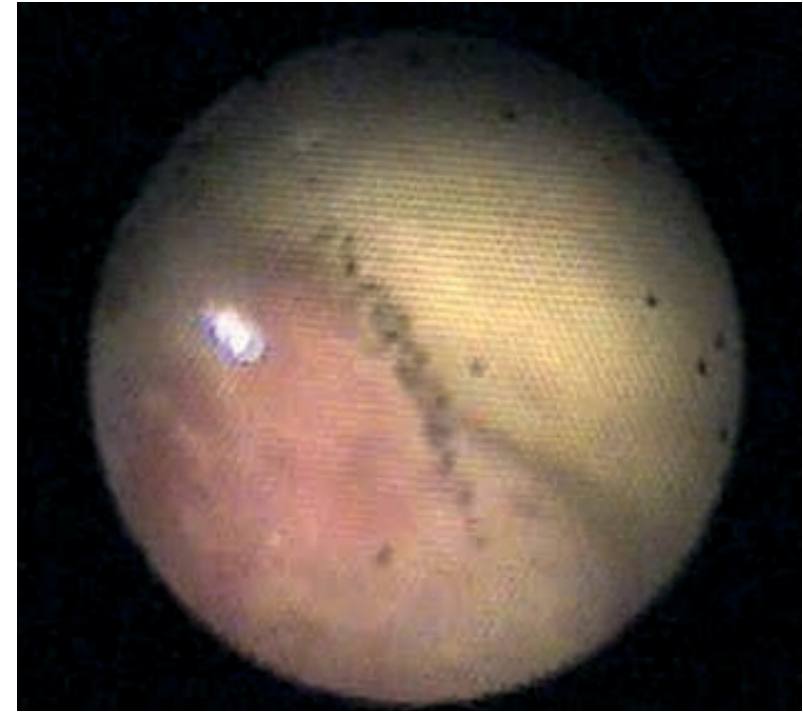

Figure 4. A 2-cm by 2-cm Ulcer in the Remaining Part of the Stomach

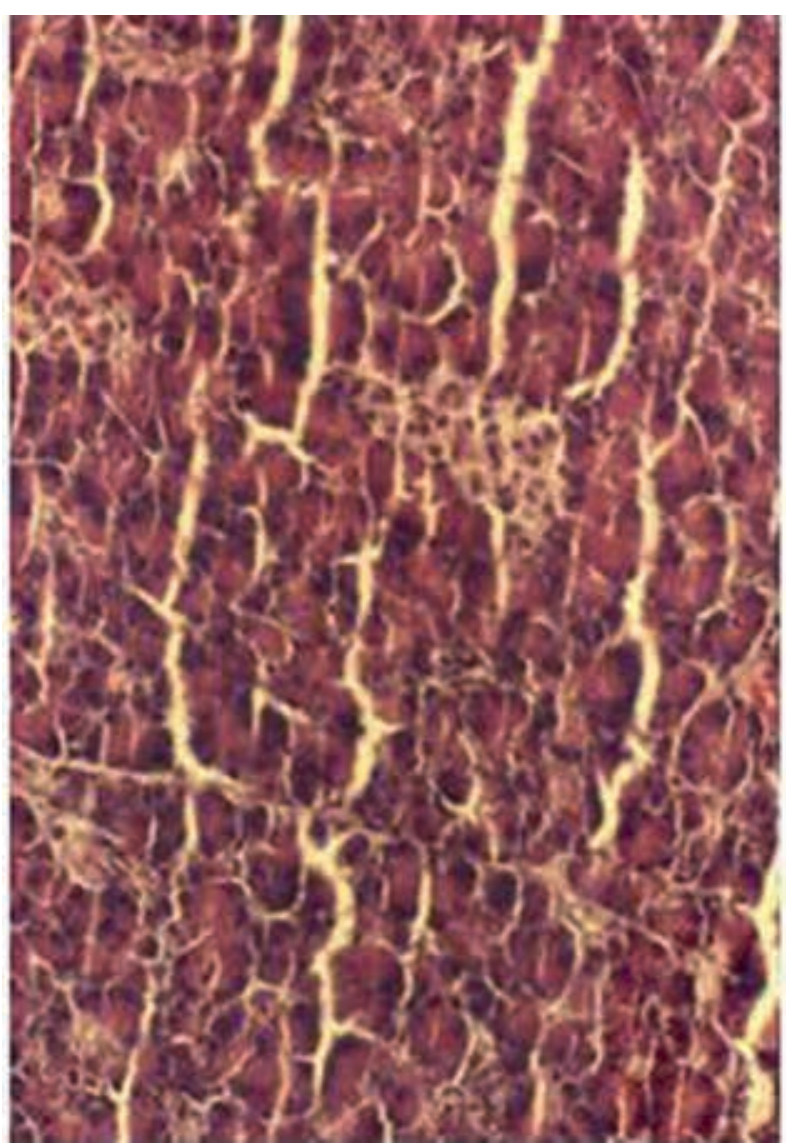

Figure 5. Microscopic View of the Pancreatic Sections

1 animal of group A (Figure 4). Macroscopic pathologic evaluation revealed normal healing of the incisional scars, without any inflammation, abscess, adhesion, or other acute or chronic inflammatory reactions. The abdominal organ topographies were normal, and no peritonitis signs were evident. Some minor adhesions were noted between the abdominal organs in both

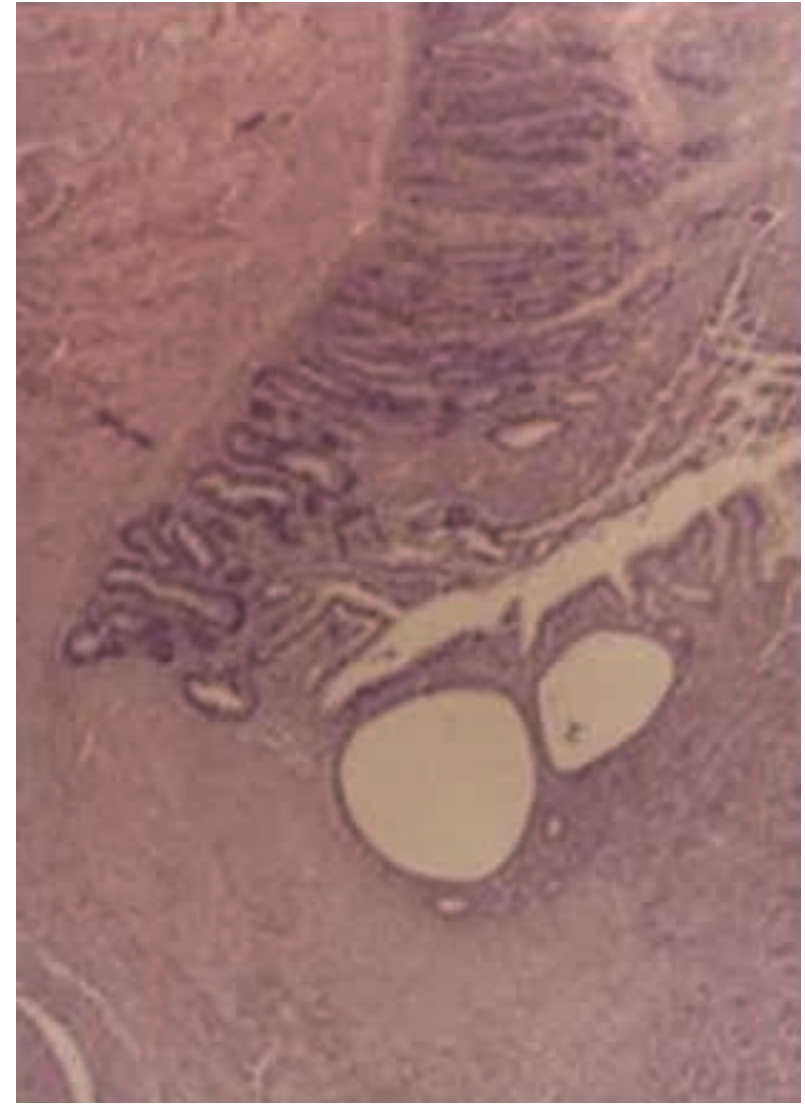

Figure 6. Gastrojejunal Anastomotic Site with Cystic Dilatation of the Jejunal Crypts

the group one and three months after the surgery: between the left quadrate lobe of the liver and epicolon and mesenteric adhesion to the anastomotic region in group B and duodenal adhesion to the left lateral lobe of the liver and liver adhesion to the duodenal pouch in group A. The morphological appearance of the esophagus, liver, gall bladder, urinary bladder, and lymph nodes were normal. In most of the animals, the gastrointestinal tract was devoid of food and contained mucosal cells and bile salts; there was no obstruction in the biliary tract of any animal. In one animal from group A, a $2 \times 2 \mathrm{~cm}$ ulcerated polyp was noted in the remaining part of the stomach one month after the surgery; some petechiae were found on the gastric wall. Macroscopic evaluation of the anastomotic regions showed normal healing with no evidence of abscess or inflammatory changes, necrosis, hemorrhage, stenosis or obstruction, fistula, and leakage.

Microscopic examination of the pancreatic sections from all animals revealed normal appearance of the gland structure, Langerhans islets, and ductal systems, without any inflammatory reaction. However, in most of the cases, there was a decrease in the number of zymogen granules (Figure 5). The junction of esophagus to stomach in all the animals had normal appearance, and there were no inflammatory, degenerative, proliferative, hypoplastic, necrotic, hemorrhagic, edemic, and ulcer- 
ative changes. There were no pathologic abnormalities in the sections obtained from the esophagogastric junction. At three months after the operation, some changes at the anastomotic sites were noted; these included increase in the number of mucus-producing cells, creation of fibrotic connective tissue involving many vessels, and no acute inflammatory lesions. In one animal from group B, sub-acute gastritis with ulcer was noted in the remaining part of the stomach. At one month after the operation, the following changes were noted: increase in the number of lymphoidal cells in the mucosal lamina propria; increase in the number and size of lymphoid follicles in the remaining part of the stomach; no ulcerative lesions in most of the cases; increase in the number of goblet cells; mucosal necrosis and ulceration with neutrophil infiltration in 1 animal from group A. Suture material being absorbed and surrounded with lymphocyte, macrophages and giant cells.

The healing was good at the gastrojejunal anastomotic sites in all the animals. The thickness of the stomach next to the anastomotic site was reduced, and cystic dilatation of the jejunal crypts was noted (Figure 6). In one animal from group A, a large ulcer with necrotic cells, fibrinous inflammatory exudate, hemorrhage, and bacterial colonies were noted at the anastomotic site at 1 month after the surgery. Histologic evaluation revealed normal appearance of other organs such as the jejunum, duodenum, ileum, colon, liver, spleen, gall bladder, and lungs.

\section{Discussion}

LADG is a minimally invasive surgery that affords faster recovery of gastrointestinal functions and lesser pain than that afforded with conventional open gastrectomy (28). In this study, there were no complications and mortality noted 1 and 3 months after the surgery. Gross pathologic examination showed no food in the intestine. Some animals developed diarrhea and showed increased intestinal motility. However, some investigators believe that resection of the gastrointestinal tract can impair the normal motility of the intestine by damaging the gastrointestinal tract pacemakers (29). The esophagus is the most sensitive to the gastric juice of the gastrointestinal tract (30). Nehra et al. showed that the concentration of intra-esophageal bile acids influence the degree of esophageal mucosal injury (31), whereas Gotley et al. showed that bile acids and trypsin were not important in the pathogenesis of reflux esophagitis (32). Cross and Wangensteen reported that bile was directly diverted from the duodenum into the esophagus in cats and dogs; this caused severe esophageal mucosal lesions in the absence of gastric acid (33). Some investigators believe that this complication can be avoided by altering the reconstruction method; however, the optimal reconstruction method still remains controversial $(9,22,23)$. No changes in the esophagus were noted in the animals after reconstruction with R\&Y and JLI, as revealed by endoscopic, gross pathologic, and microscopic histo- logic evaluations. However, two animals (one from each group) developed ulcerative gastritis in the remaining part of stomach. This could be because of billiary reflux in the stomach and induced reflux gastritis since endoscopic evaluation revealed the presence of bile juice in the stomach. Tonelli et al. reported endoscopic and histological esophagitis in four of six patients (66\%) who had undergone total gastrectomy: in one of the three (33\%) patients who had undergone reconstruction with JPI and in all three (100\%) patients who had undergone reconstruction with R\&Y (34).

Several studies have reported an increased incidence of pancreatic cancer in patients undergoing gastric resection (18-20). Significant exocrine pancreatic trophism has been reported after partial or total gastrectomy in rats (19). Buchler reported vagotomy-induced pancreatic hyperplasia, enzyme dissociation, and decreased basal amylase discharge in vitro (35). These studies reported the presence of abundant cytoplasmic zymogen granules in the gastrectomized patients. On the other hand, we found reduced number of zymogen granules in the pancreas; this could be because the animals were restricted from over feeding in our study. During total gastrectomy, most gastropancreatic nerves are destroyed; this can cause denervation of the pancreas. The mechanism underlying gastrectomy-induced development of pancreatic cancer is unclear; increased concentrations of CCK after gastrectomy might mediate pancreatic carcinogenesis (19).

Histological evaluation revealed good healing of the anastomotic regions in all animals, but some animals showed chronic inflammatory response. This could be because of the bacterial flora and its infiltration to the jejunum which had been trapped between the tissues and sutures at the jejonal anastomotic sites. There were no significant differences between the two groups with regard to macroscopic and histological findings. In conclusion, upper gastrointestinal endoscopy is a useful and feasible technique to detect esophageal gastritis, anatomical structure, obstruction, or stenosis; and other disorders of the upper gastrointestinal tract. The two reconstructive techniques- R\&Y and JLI-yielded similar endoscopic and pathologic findings.

\section{Acknowledgments}

The authors thank Research Council, Veterinary Faculty, University of Tehran, Center of Excellence For Veterinary Research on Iranian Indigenous Animals, and MIS Center, Rassuleakram Hospital, for providing financial support for this research.

The authors would also like to thank the Research Council, Veterinary Faculty, University of Tehran, for providing ethical permission to perform the experimental research under the supervisionary animal care committee.

\section{Authors' Contribution}

None declared. 


\section{Financial Disclosure}

None to declare.

\section{Funding/Support}

None to declare.

\section{References}

1. Levine MS, Fisher AR, Rubesin SE, Laufer I, Herlinger H, Rosato EF. Complications after total gastrectomy and esophagojejunostomy: radiologic evaluation. AJR Am J Roentgenol.1991;157(6):118994.

2. Kim MC, Choi HJ, Jung GJ, Kim HH. Techniques and complications of laparoscopy-assisted distal gastrectomy (LADG) for gastric cancer. Eur J Surg Oncol. 2007;33(6):700-5.

3. Lopes AG, Jr., Rodrigues CJ, Lopes LH, Vilca-Melendez H, Rodrigues AJ, Jr. Differences in tumour growth, tumour cell proliferation and immune function after laparoscopy and laparotomy in an animal model. HPB (Oxford). 2001;3(3):213-7.

4. Redmond HP, Watson RW, Houghton T, Condron C, Watson RG, Bouchier-Hayes D. Immune function in patients undergoing open vs laparoscopic cholecystectomy. Arch Surg. 1994;129(12):1240-6.

5. Sietses C, Havenith CE, Eijsbouts QA, van Leeuwen PA, Meijer $\mathrm{S}$, Beelen RH, et al. Laparoscopic surgery preserves monocytemediated tumor cell killing in contrast to the conventional approach. Surg Endosc. 2000;14(5):456-60.

6. Hiki N, Shimizu N, Yamaguchi H, Imamura K, Kami K, Kubota K, et al. Manipulation of the small intestine as a cause of the increased inflammatory response after open compared with laparoscopic surgery. BrJ Surg. 2006;93(2):195-204.

7. Kitano S, Iso Y, Moriyama M, Sugimachi K. Laparoscopy-assisted Billroth I gastrectomy. Surg Laparosc Endosc. 1994;4(2):146-8.

8. Lahey FH, Marshall SF. Should total gastrectomy be employed in early carcinoma of the stomach; experience with 139 total gastrectomies. Ann Surg. 1950;132(3):540-65.

9. Tokunaga M, Ohyama S, Hiki N, Hoshino E, Nunobe S, Fukunaga $\mathrm{T}$, et al. Endoscopic evaluation of reflux esophagitis after proximal gastrectomy: comparison between esophagogastric anastomosis and jejunal interposition. World J Surg. 2008;32(7):1473-7.

10. Nishijima K, Miwa K, Miyashita T, Kinami S, Ninomiya I, Fushida $S$, et al. Impact of the biliary diversion procedure on carcinogenesis in Barrett's esophagus surgically induced by duodenoesophageal reflux in rats. Ann Surg. 2004;240(1):57-67.

11. Yumiba T, Kawahara H, Nishikawa K, Inoue Y, Ito T, Matsuda $\mathrm{H}$. Impact of esophageal bile exposure on the genesis of reflux esophagitis in the absence of gastric acid after total gastrectomy. Am J Gastroenterol. 2002;97(7):1647-52.

12. Huscher CG, Mingoli A, Sgarzini G, Sansonetti A, Di Paola M, Recher A, et al. Laparoscopic versus open subtotal gastrectomy for distal gastric cancer: five-year results of a randomized prospective trial. Ann Surg. 2005;241(2):232-7.

13. Nakane Y, Okumura S, Akehira K, Okamura S, Boku T, Okusa T, et al. Jejunal pouch reconstruction after total gastrectomy for cancer. A randomized controlled trial. Ann Surg. 1995;222(1):27-35.

14. Inberg MV, Heinonen R, Lauren P, Rantakokko V, Viikari SJ. Total and proximal gastrectomy in the treatment of gastric carcinoma: a series of 305 cases. World J Surg. 1981;5(2):249-57.

15. Lygidakis NJ. Total gastrectomy for gastric carcinoma: a retrospective study of different procedures and assessment of a new technique of gastric reconstruction. Br J Surg. 1981;68(9):649-55.

16. Walther B, Lowenhielm P, Strand SE, Stahlberg F, Uvelius B, Oscar- son J, et al. Healing of esophagojejunal anastomoses after experimental total gastrectomy. A comparative study using manually sutured or stapled anastomoses. Ann Surg. 1986;203(4):439-46.

17. Hosono S, Arimoto Y, Ohtani H, Kanamiya Y. Meta-analysis of short-term outcomes after laparoscopy-assisted distal gastrectomy. World J Gastroenterol. 2006;12(47):7676-83.

18. Caygill CP, Hill MJ, Hall CN, Kirkham JS, Northfield TC. Increased risk of cancer at multiple sites after gastric surgery for peptic ulcer. Gut. 1987;28(8):924-8.

19. Saraydin SN, Koptagel E. Early Morphological Changes after Total Gastrectomy in the Rat Pancreas. Turk J Vet Anim Sci. 2005;29:11926.

20. Tersmette AC, Offerhaus GJ, Giardiello FM, Tersmette KW, Vandenbroucke JP, Tytgat GN. Occurrence of non-gastric cancer in the digestive tract after remote partial gastrectomy: analysis of an Amsterdam cohort. Int J Cancer. 1990;46(5):792-5.

21. Watanapa P, Williamson RC. Experimental pancreatic hyperplasia and neoplasia: effects of dietary and surgical manipulation. BrJ Cancer. 1993;67(5):877-84.

22. Ichikawa D, Ueshima Y, Shirono K, Kan K, Shioaki Y, Lee CJ, et al. Esophagogastrostomy reconstruction after limited proximal gastrectomy. Hepatogastroenterology. 2001;48(42):1797-801.

23. Shiraishi N, Adachi Y, Kitano S, Kakisako K, Inomata M, Yasuda K. Clinical outcome of proximal versus total gastrectomy for proximal gastric cancer. World J Surg. 2002;26(9):1150-4.

24. Gowen GF. Delayed gastric emptying after Roux-en-Y due to four types of partial obstruction. Ann Surg. 1992;215(4):363-7.

25. Brundage SI, Maier RV, Jurkovich GJ. Re; Witzke JD et al. Stapled versus hand sewn anastomes in patients with small bowel injury: a changing perspective. J Trauma. 2000;49:660--665. J Trauma. 2001;51(1):180-2.

26. Caporossi C, Cecconello I, Aguilar-Nascimento JE, Venço F, Gama-Rodrigues JJ. Hand-sewn and stapled esophageal anastomosis: experimental study in dogs. Acta Cirurgica Brasileira. 2004;19:319-27.

27. Celis J, Ruiz E, Berrospi F, Payet E. [Mechanical versus manual suture in the jejunal esophageal anastomosis after total gastrectomy in gastric cancer]. Rev Gastroenterol Peru. 2001;21(4):271-5.

28. Park JM, Jin SH, Lee SR, Kim H, Jung IH, Cho YK, et al. Complications with laparoscopically assisted gastrectomy: multivariate analysis of 300 consecutive cases. Surg Endosc. 2008;22(10):21339.

29. Pan Y, Li Q, Wang DC, Wang JC, Liang H, Liu JZ, et al. Beneficial effects of jejunal continuity and duodenal food passage after total gastrectomy: a retrospective study of 704 patients. EurJ Surg Oncol. 2008;34(1):17-22.

30. Skinner HH, Merendino KA. An experimental evaluation of an interposed jejunal segment between the esophagus and the stomach combined with upper gastrectomy in the prevention of esophagitis and jejunitis. Ann Surg. 1955;141(2):201-7.

31. Nehra D, Howell P, Pye JK, Beynon J. Assessment of combined bile acid and $\mathrm{pH}$ profiles using an automated sampling device in gastro-oesophageal reflux disease. BrJ Surg. 1998;85(1):134-7.

32. Gotley DC, Appleton GV, Cooper MJ. Bile acids and trypsin are unimportant in alkaline esophageal reflux. J Clin Gastroenterol. 1992;14(1):2-7.

33. Cross FS, Wangensteen $\mathrm{OH}$. Role of bile and pancreatic juice in production of esophageal erosions and anemia. Proc Soc Exp Biol Med.1951;77(4):862-6.

34. Tonelli F, Corazziari E, Spinelli F. Evaluation of "alkaline" reflux esophagitis after total gastrectomy in Henley and Roux-en-Y reconstructive procedures. World J Surg. 1978;2(2):233-7.

35. Buchler M, Malfertheiner P, Friess H, Eiberle E, Beger HG. Gut peptide-mediated adaptive response of the exocrine pancreas. Scand J Gastroenterol Suppl.1988;151:114-22. 